$>$ perhaps, but authentic Hawaiian ones. Being authentic does not involve having native or endemic species or being devoid of people, and is thus a more tractable environmental goal than achieving naturalness or wildness.

Neither volume tries to dismiss 'natural nature' as the cause célèbre of conservation; rather, both encourage adding unnatural nature to that which we seek to preserve. Well protected places that are rich in endemics are important, but rambunctious gardens and authentic ecosystems are crucial too.

Take a modern New England forest. Its ecology consists of garlic mustard from Europe, thorny Japanese barberry, introduced earthworms, soil that is enriched with industrial nitrogen, exotic insect pests such as hemlock woolly adelgids, Asian longhorned beetles and emerald ash borers, and an ungodly number of ravenous deer who know no serious predation. It is a rambunctious garden. It is polluted, stunted, diseased, unstable and has no top predators. But it is teeming with life. It is home to surviving native species; exhibits ecosystem functions such as storing carbon and cycling nutrients; and even provides some ecosystem services by stabilizing the hilly slopes and supplying deer for hunters in the region. This is authentic nature in the Anthropocene epoch.

Yet ecological theory still holds, even if it is complex and inconvenient. If nature is any set of interacting species, through which energy flows and nutrients cycle, then it calls for saving too many species and setting aside too much land. Yet I would caution against making intelligent-design-like arguments that would dispense with ecology, to replace it with something simpler. Nature without ecology is like biology without evolution; neither is viable, neither makes sense.

Marris and Dudley challenge us to revisit the definition of nature in our increasingly unnatural world. But modern ecosystems that are haphazardly assembled from the remains of human development are unpredictable and fragile. With one billion people hungry, two billion poor and three billion in desperate need of water, the hopes of humanity rest on conserving, restoring and sustainably managing the services that nature provides. The bigger question is whether the unnatural nature that we have wrought, although familiar in form and function, will save us or prove to be monstrous.

Shahid Naeem is professor of ecology at Columbia University, New York, USA. e-mail:sn2121@columbia.edu

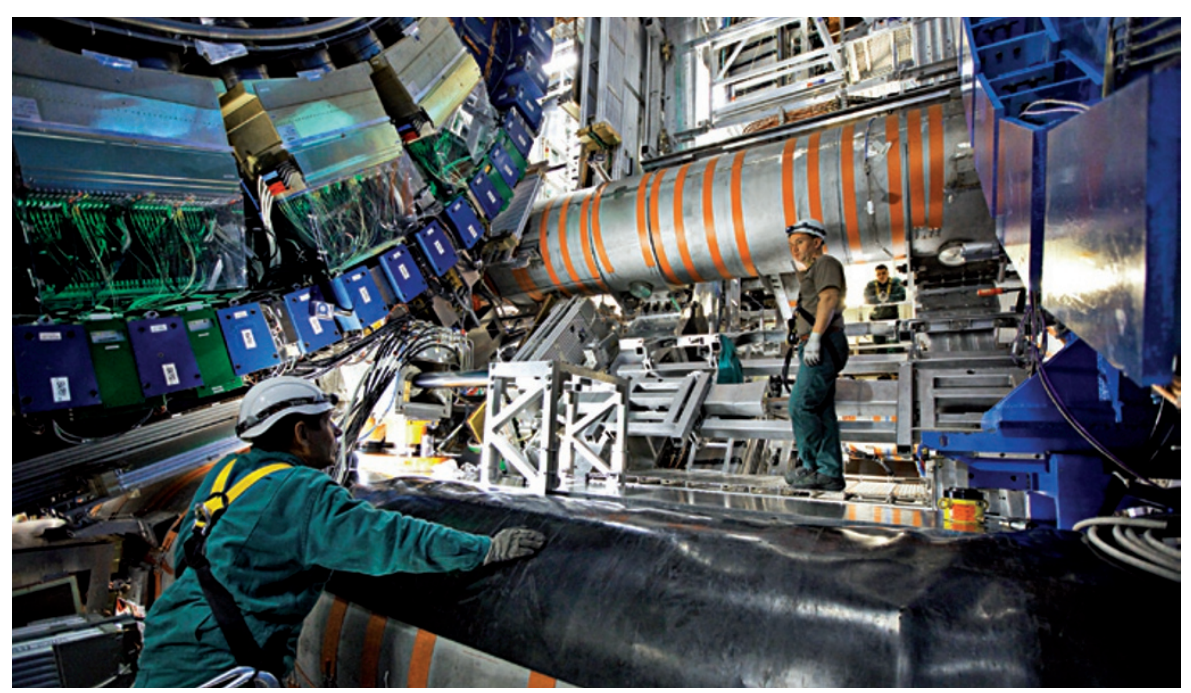

Building the Large Hadron Collider proved tricky, not least because of fears it would create tiny black holes.

PARTICLE PHYSICS

Inside the collider

Joseph Silk enjoys an eloquent take on the Higgs boson, supersymmetry and the world's largest particle smasher.
$\mathrm{M}$ entioning particle physics may silence many dinner parties, but that has not deterred its funders. By the end of 2010, more than $€ 7$ billion (US $\$ 10$ billion) had been ploughed into the current world-leading machine in experimental particle physics - the Large Hadron Collider (LHC) at CERN, Europe's highenergy physics lab near Geneva, Switzerland. So it behooves the researchers involved to communicate the relevance of the LHC's science goals to the public.

Lisa Randall's Knocking on Heaven's Door is the latest attempt to do so. Her eloquent book details the trials and tribulations of the LHC, from conception to implementation, and takes us on a grand tour of the underlying science. Randall, a professor of physics at Harvard University in Cambridge, Massachusetts, and a leading contributor to particle-physics theory, borrows her title from Bob Dylan's soundtrack to the 1973 Sam Peckinpah film, Pat Garrett and Billy the Kid. The film is a lament on the death of a gunslinger - and the book's title may be a reference to the prediction that turning on the LHC would result in the destruction of Earth. Fortunately, as Randall describes, this did not happen.

That prediction provides a measure of the LHC's reach, and its hold on the public's imagination. Physicists' ultimate dream is to unify the fundamental interactions of physics. This involves combining
Lisa Randall's

hyperspace opera:

go.nature.com/ydazso

\section{$\rightarrow$ NATURE.COM}

gravity with quantum theory and, in particular, with the forces that hold particles and atoms together in higher dimensions of space and time.

String theorists, whose ranks purportedly include the greatest brains in physics, have predicted that infinitesimal, very short-lived black holes are the unifying factor, the missing glue. Some have predicted that these microscopic objects could

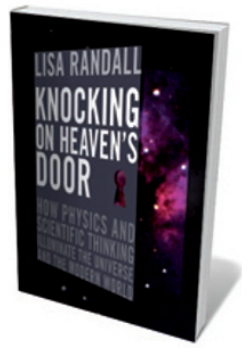

Knocking on Heaven's Door: How Physics and Scientific Thinking Illuminate the Universe and the Modern World LISA RANDALL Bodley Head: 2011. 464 pp. £20 be recreated in sufficiently high-energy particle collisions with a powerful particle accelerator such as the LHC. However, most particle physicists doubt that they will actually see such events - Stephen Hawking predicted that, owing to quantum physical effects, microscopic black holes should decay in a fraction of a nanosecond.

But even Hawking might be fallible. Richard Feynman famously said that "nobody understands quantum mechanics". If Hawking was wrong, an escaping black hole might suck up its surroundings: the LHC itself and Geneva (to which humanity could no doubt adapt) and even Earth. Pursuing this logic, a teacher in Hawaii combined 
forces with a Spanish writer in 2008 to file a lawsuit against CERN, the US Department of Energy and the US National Science Foundation that threatened to block the start-up of the LHC.

As Randall describes, scientists responded with fervour. It turns out that nature provides an answer to such concerns. Cosmic rays pervade space and bombard Earth continuously. Their energies extend to billions of times that achievable by the LHC. Had microscopic black holes been created in high-energy collisions of cosmic-ray particles, Earth and the stars would have been swallowed up long ago. Physicists could relax: the LHC risk-assessment exercise was favourably resolved.

On 20 November 2009, the LHC first powered up for experiments. By the end of 2012 it will reach a high enough energy to test the standard model of particle physics and to detect the Higgs boson, the elusive, mass-giving 'God particle' - if it exists. Knocking on Heaven's Door describes how that discovery would confirm one of the great predictions of physics. In parallel, the LHC will search for physics beyond the standard model. One of the most anticipated signatures will be that of supersymmetry, a new field that provides a candidate particle for dark matter.

Given her background, Randall naturally complements her discussion of the LHC by describing ongoing searches for dark matter that are mostly led by particle physicists. For them, the driving question is: what is it? But Randall largely ignores astronomers' contribution to the problem - namely, giving the empirical motivation for dark matter (it is the dominant form of matter in the Universe) and mapping its location.

The LHC could resolve the greatest mysteries of the Universe: one microscopically small, and the other macroscopically large. But suppose physicists fail to detect any sign of the Higgs boson or supersymmetry? Will we have wasted those billions? Failure would shift the goal posts. Exploration of the next particle-physics frontier will require more powerful, more expensive and less attainable machines. But we would also be unsure as to how high we would need to go in terms of energy or luminosity to achieve a breakthrough in new physics. Visionary ideas would be needed.

Let us hope that the LHC does find something. And that, regardless of the outcome, the inspired efforts of its builders will combine with theorists' dreams to develop new and affordable probes of the ultimate horizons of the Universe.

Joseph Silk is professor of physics at the Institut d'Astrophysique, Université Pierre et Marie Curie, Paris, France. e-mail:silk@astro.ox.ac.uk

\section{Books in brief}

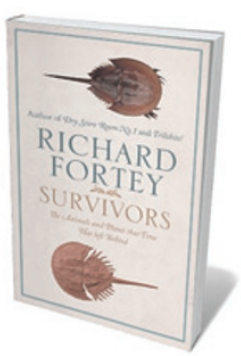

Survivors: The Animals and Plants that Time Has Left Behind Richard Fortey HARPER PRESS 400 pp. £25 (2011)

Cataclysms come and go, but the stromatolites of Western Australia have sat them out for more than 2 billion years. These organic cushion-like structures with cyanobacterial wigs lead palaeontologist Richard Fortey's cast of survivors still dangling from the tree of life. He roves from hordes of horseshoe crabs in Delaware Bay on the northeast US coast to New Zealand's velvet worms and beyond, each fascinating organism a focus for broader thoughts on evolutionary history. Decades spent "looking at thoroughly dead creatures" have not dimmed Fortey's ability to bring these relics to life.

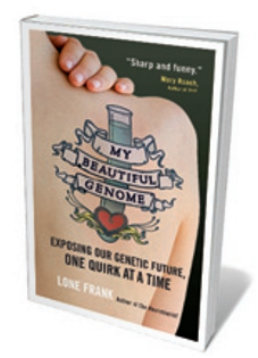

My Beautiful Genome: Discovering Our Genetic Future, One Quirk at a Time

Lone Frank ONEWORLD 320 pp. £10.99 (2011)

As consumer-led genomics ramps up, questions of ethics and efficacy proliferate. Neurobiologist Lone Frank looks at how exposing our DNA affects our lives. Having interviewed James Watson and covered the rise of personal genomics from 2008, Frank puts her own genes to the test. She charts the range of applications - deep ancestry, disease, behaviour and personality, mental illness and partner compatibility - and concludes that, far from being a straitjacket, unveiling our 'invisible self' liberates, connects and reassures.

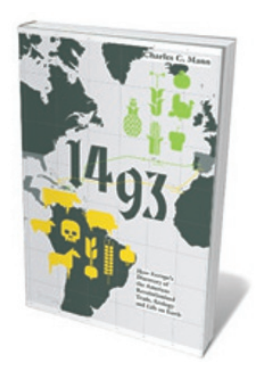

\section{3: How Europe's Discovery of the Americas Revolutionized} Trade, Ecology and Life on Earth

Charles C. Mann GRANTA 544 pp. 14.99 (2011)

Journalist Charles Mann chronicles how Christopher Columbus' second New World expedition in 1493 triggered a global upheaval. European vessels left sheep, rats and lethal viruses in the New World and carried tomatoes, tobacco and maize (corn) to the Old. Millions of people died from introduced diseases and ecosystems convulsed. A world economy emerged, propelled by trade in commodities from silk to slaves. Drawing on new research, Mann reframes the past 500 years to riveting effect.

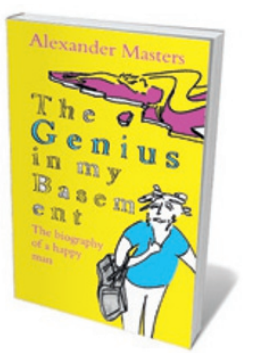

The Genius in my Basement: The Biography of a Happy Man Alexander Masters FOURTH ESTATE 352 pp. £8.99 (2011) In 2007, writer Alexander Masters - author of Stuart: A Life Backwards (2006) - lived above the distinguished mathematician Simon Phillips Norton in Cambridge, UK. Norton helped to devise the 'monstrous moonshine' conjecture, about a mathematical symmetry group in thousands of dimensions known as the Monster; he is also an eccentric who obsesses about buses and Bombay mix. Masters, with his background in maths and physics, has written a fond yet merciless portrait that attempts both to dissect the Monster and to do justice to an extraordinary character.

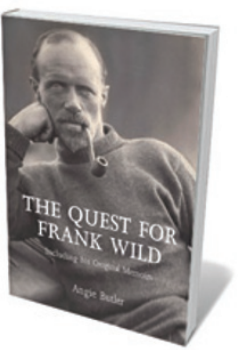

The Quest for Frank Wild

Angie Butler JACKLEBERRY PRESS 224 pp. £25 (2011)

Antarctic exploration is synonymous with heroes such as Ernest Shackleton, Robert Falcon Scott and Roald Amundsen. Few of us have heard of Frank Wild, Shackleton's 'right-hand man', who had pivotal roles in five Antarctic expeditions and is one of only two men to be awarded a Polar Medal with four bars. After seven years tracking Wild's fate, writer Angie Butler redresses the balance. Her account of his life includes a coup: Wild's memoir of four expeditions, including Nimrod and Endurance, is published here for the first time. 